\title{
Editorial
}

\section{Plagiarism in dentistry}

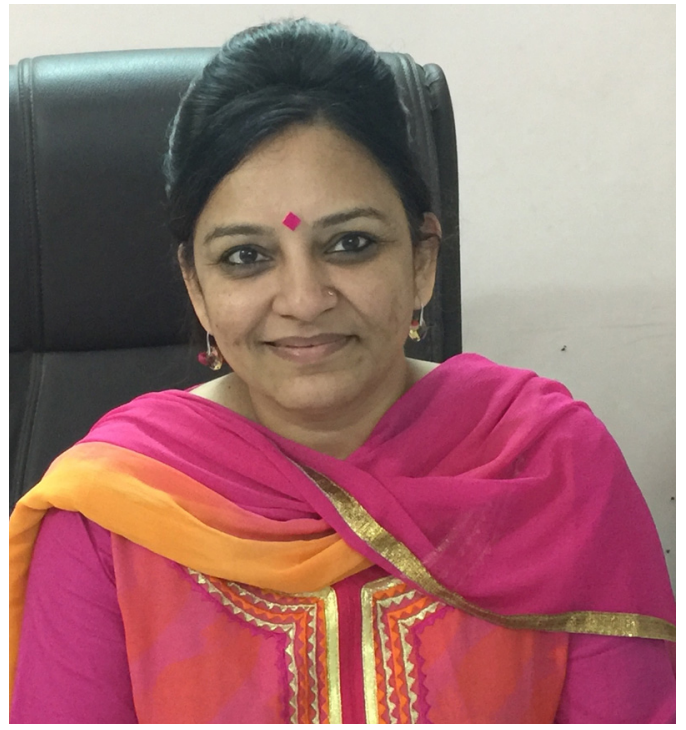

Dental Sciences, today, is flooded with information due to improved tools of communications and increased access to vast pool of knowledge available online. While this has increased affordability to quality knowledge and has linked nations into web of one, this has also led to increased potential of misusing this information. Plagiarism is one such major misuse. The Merriam-Webster Online Dictionary describes Plagiarism as

- to steal and pass off (the ideas or words of another) as one's own

- to use (another's production) without crediting the source

- to commit literary theft

- to present as new and original an idea or product derived from an existing source

Thus plagiarism involves fraud which is an offence in all penal codes of world. Students and even experts in the field often become both victims and perpetrators of this crime. While this has been happening in medical sciences, increased number of journals, both online and offline, increased number of post graduate seats and fierce competition for faculty positions has ignited spurt of this offence in field of dental sciences. Many a times people are unaware of the nature of their act, but this does not exempt them from criminal liability as old adage of law says no knowledge of local law is not a valid defence. International laws such as Intellectual property rights, patent laws and copyrights have transnational claws. Therefore one has to be aware of these and follow them in true spirit. Then comes your own motive. Plagiarism involves bad motive that is berefting due worthy of his/her credit to something of which he/she is the creator. Bad motive, therefore, is evident when credit is taken for something when actually you are not true owner. This can be through words, actions and signs. Thus plagiarism is very wide term and involves bad motive coupled with the fraud action.

While plagiarism is prevalent in all field of knowledge we are here concerned more with publications. Most of the journals today check for plagiarism and tools like ithenticate, Retraction Watch keep a track of all authors blacklisted. Publication ethics should always be the guiding post. There are many reputed organisations, who have come up with a set of publication ethics also freely available on net. Therefore it is always better to look for source of any information and give due reference to it while quoting.

Coexistence recognizing the natural rights of others is the hallmark of progressive civilization. Becoming a Human with large and open heart is akin to becoming a successful academician. Therefore sincere advice for all is to be Original and Truthful to Yourself.

Divya Mehrotra

http://dx.doi.org/10.1016/j.jobcr.2016.04.002

2212-4268/

(C) 2016 Published by Elsevier B.V. on behalf of Craniofacial Research Foundation. 